\title{
Relationship Between Shell Discoloration of Pistachio Nuts and Incidence of Fungal Decay and Insect Infestation
}

\author{
Mark A. Doster and Themis J. Michailides, Department of Plant Pathology, University of California, \\ Davis/Kearney Agricultural Center, Parlier 93648
}

\begin{abstract}
Doster, M. A., and Michailides, T. J. 1999. Relationship between shell discoloration of pistachio nuts and incidence of fungal decay and insect infestation. Plant Dis. 83:259-264.

Shell discoloration of pistachio (Pistacia vera) nuts collected from commercial orchards and processing plants was related to fungal decay and insect infestation of the kernel. Nuts with ruptured hulls (early split nuts and nuts with cracked hulls) varied considerably in the amount of shell discoloration, ranging from none to extensive. For both types of hull rupture, as shell discoloration increased, kernel decay also increased. Nuts with no discoloration had little or no fungal decay and navel orangeworm (Amyelois transitella) infestation. Processed nuts with an oily-shell appearance had the highest incidences of fungal decay and navel orangeworm infestation; nuts with a crinkled shell, nuts with extensive dark brown discoloration, and nuts with moderate dark brown discoloration along the suture had relatively high levels of decayed and infested kernels; while nuts with yellow discoloration, nuts with moderate dark brown discoloration not along the suture, and nuts with no discoloration had little or no decay and infestation. Also, as shell discoloration of processed nuts increased, kernel decay increased. Our results suggest that shell characteristics may be used by processors to identify poor quality nuts and to improve the quality of pistachio nuts sold to consumers.
\end{abstract}

Additional keywords: Alternaria, Aspergillus, Ulocladium

The hull of the pistachio (Pistacia vera L.) nut normally functions as an important barrier to invasion of the kernel by fungi and insects, especially after the shell has split. Two types of hull rupture occur before harvest. In the first type, early splitting, the hull ruptures along the shell split. In the second type, cracking of the hull, the hull ruptures elsewhere. Hull cracking has also been called "growth splitting" (25). Typically, early split nuts are more likely to have kernel decay than nuts with cracked hulls (5). Pistachio nuts, particularly those with ruptured hulls, are decayed by many different fungi, including more than 10 different Aspergillus spp., numerous Penicillium spp., and other fungi such as Alternaria and Ulocladium $(5,12,22)$. Decay of nuts by Aspergillus spp. is important because these fungi produce the widely regulated aflatoxins (29) and other mycotoxins (23). In addition, pistachio nuts with ruptured hulls are frequently infested with insects, especially the larvae

Corresponding authors: Mark A. Doster and Themis J. Michailides; E-mail: mark@uckac.edu, themis@uckac.edu

This research was supported by USDA Cooperative Research Agreement No. 58-5325-1-194 and 58-5325-6-844.

Accepted for publication 8 December 1998.

Publication no. D-1999-0119-01R

(C) 1999 The American Phytopathological Society of navel orangeworm (Amyelois transitella (Walker)) (26). Nuts infested with navel orangeworm are more likely to be moldy and contaminated with aflatoxins than are noninfested nuts $(5,28)$.

The hull is removed during the early stages of processing, so the appearance of the hull cannot be used to distinguish nuts likely to be moldy from normal nuts. Therefore, other characteristics are needed to identify in-shell nuts with moldy kernels. Both early split nuts and nuts with cracked hulls tend to be smaller in size, lighter in weight, and have more shell discoloration than nuts with intact hulls $(5,25)$. Although any of these characteristics might help identify moldy pistachio nuts, the easiest characteristic to use probably would be discoloration of the external shell. The shells of early split nuts frequently have a distinctive dark brown discoloration along the shell suture $(3,5,25)$

Even though previous research showed that pistachio nuts with ruptured hulls tend to have discolored shells and kernel decay $(4,5)$, the quantitative relationship between shell discoloration and kernel decay was not determined. The goal of this research was to determine shell characteristics that processors could use to remove nuts with kernel decay and insect infestation. The specific objective was to determine the relationship between types and amounts of shell discoloration and incidence of fungal decay and insect infestation of the kernel of nuts from commercial orchards at har- vest and of nuts from processing plants after storage.

\section{MATERIALS AND METHODS}

Collection of samples from orchards. Nut samples with hulls were collected during the normal harvest period from eight commercial pistachio orchards (all cultivar Kerman) in California (orchards A and $\mathrm{G}$ in Tulare County, orchards B to F in Madera County, and orchard $\mathrm{H}$ in Merced County). Samples were collected from orchard A on 27 August 1992 (524, 115, and 279 early split nuts, nuts with cracked hulls, and normal nuts with intact hulls, respectively), orchard $\mathrm{B}$ on 31 August $1992(123,449,56)$ and 7 September 1993 (235, 0,180$)$, orchard C on 3 September $1992(0,356,0)$, orchard D on 3 September $1992(0,127,0)$, orchard E on 7 September $1993(151,0,180)$, orchard F on 10 September $1996(1,600,125,56)$, orchard G on 3 and 13 September 1996 (totals for both harvests, 1,107, 735, 2,125), and orchard H on 10 and 20 September 1997 (totals for both harvests, 1,668, 481, 2,132). Most pistachio nuts split their shells in the orchard prior to harvest, so only nuts with split shells were evaluated. Samples were stored at 0 to $1^{\circ} \mathrm{C}$ for a short period until the hull was removed and the nut evaluated, although in some cases after hull removal, nuts were stored at $-19^{\circ} \mathrm{C}$.

Collection of samples from processing plants. Pistachio nut samples were collected from two processing plants in the San Joaquin Valley of California in 1994. Samples were collected on 23 February from processor A and on 13 April (bin 1), 17 June (bin 2), and 4 August (bin 3) from processor B. These nuts had been partially processed; that is, the nuts had their hulls removed and were dehydrated, and nuts that were very small or light in weight had been removed. After collection from the processors, the nut samples were stored at $-19^{\circ} \mathrm{C}$.

Evaluation of nut samples. Shells of the nuts from orchards and processors were evaluated for two types of external discoloration: discoloration around the shell suture and a general discoloration that was not restricted to any specific location (5). The nuts from orchards $\mathrm{G}$ and $\mathrm{H}$ were not evaluated for discoloration around the suture. The nuts from processor A and processor B (bins 1 and 2) were separated according to whether the shell discoloration was dark brown or yellow. A pretrans- 
formed scale (18) was used to rate the amount of general shell discoloration: $0=$ $0 \%$ of shell surface discolored, $1=1$ to $10 \%, 2=11$ to $35 \%, 3=36$ to $64 \%, 4=$ greater than $64 \%$. The nuts from processor $\mathrm{A}$ and processor B (bins 1 and 2 but not bin 3 ) were sorted in the laboratory into seven categories based on the external appearance of the shell, including the type and amount of discoloration. The seven categories were nonstained, oily shell appearance, crinkled shell, extensive dark brown discoloration, moderate dark brown discoloration along the suture, moderate dark brown discoloration but not along the suture, and yellow discoloration. For each category, approximately 80 nuts from each of the three samples were evaluated for fungal decay and insect infestation. In addition, 3,350 nuts from processor $\mathrm{B}$, bin 3 , were evaluated for shell discoloration but not sorted into the seven categories.

After removing the shells by hand, the kernels were examined using a dissecting microscope $(10 x)$ for the presence of fungi and navel orangeworm infestation. If fungi were observed, a dissecting microscope (60x) was used to further identify the fungus using sporulating structures. All Aspergillus fungi were assigned to a section by using the size and color of the conidial heads. For orchards $\mathrm{G}$ and $\mathrm{H}$, Aspergillus fungi and dematiaceous fungi with dark, multicelled conidia were further identified by isolating the fungi into pure culture and using colony and microscopic characteristics to identify the species $(9,10,15)$.

Data analysis. Analysis of variance was used with least significant difference (LSD) for separation of means. Data in the form of percentages were sometimes transformed with the standard arcsine transformation $(17,18)$. Each category of shell appearance for early split nuts was replicated three, two, and four times for 1992, 1993, and 1996, respectively. Each category for processed nuts was replicated two and four times for processors $\mathrm{A}$ and $\mathrm{B}$, respectively. Data where an independent variable consisted of quantitative levels (such as amount of shell discoloration) were analyzed by polynomial regression (18). In a few cases, Fisher's exact test was used for counts. All analyses were done using SAS (release 6.12, SAS Institute Inc., Cary, NC).

\section{RESULTS}

Shell discoloration and kernel quality in nuts with ruptured hulls from orchards. Typically, the shells of nuts with intact hulls had little or no discoloration. Only $0.1 \%$ of 751 normal nuts with intact hulls from orchards $\mathrm{A}, \mathrm{B}, \mathrm{E}$, and $\mathrm{F}$ had discoloration along the suture. For normal nuts without suture discoloration, only

Table 1. Percentage of early split (ES) and cracked hull nuts categorized according to type of shell discoloration in pistachio nuts from commercial orchards ${ }^{y}$

\begin{tabular}{|c|c|c|c|c|c|}
\hline \multirow{2}{*}{\multicolumn{2}{|c|}{ Type of shell discoloration ${ }^{\mathrm{z}}$}} & \multicolumn{4}{|c|}{ Percent nuts } \\
\hline & & \multicolumn{2}{|c|}{1992} & \multicolumn{2}{|c|}{1996} \\
\hline Suture & General & ES & Cracked & $\mathbf{E S}$ & Cracked \\
\hline No & $0 \%$ & 9.1 & 44.9 & 13.4 & 22.4 \\
\hline No & 1 to $10 \%$ & 5.4 & 39.4 & 5.1 & 45.6 \\
\hline No & $>10 \%$ & 0.0 & 10.6 & 0.2 & 4.0 \\
\hline Yes & 1 to $10 \%$ & 42.0 & 4.8 & 38.4 & 19.2 \\
\hline Yes & 11 to $35 \%$ & 25.5 & 0.4 & 19.2 & 7.2 \\
\hline Yes & $>35 \%$ & 18.0 & 0.0 & 23.8 & 1.6 \\
\hline
\end{tabular}

${ }^{\mathrm{y}}$ The 1992 data were from orchards A and B combined (647 and 564 early splits and nuts with cracked hulls, respectively), whereas the 1996 data were from only orchard $\mathrm{F}$ (1,600 and 125 nuts). Similar results were also observed for ES in 1993 in orchards B and E.

${ }^{\mathrm{z}}$ Suture discoloration means relatively large amounts of discoloration within $2 \mathrm{~mm}$ of the shell suture or split. General shell discoloration refers to the percentage of the external shell surface that was discolored regardless of location.
$5.5 \%$ had 1 to $10 \%$ shell discoloration and only $0.1 \%$ had more than $10 \%$ of the external shell surface discolored.

Nuts with ruptured hulls varied considerably in the type and amount of shell discoloration (Table 1). For example, 9 and $13 \%$ of the shells of early split nuts had no discoloration for 1992 and 1996, respectively, while 18 and $24 \%$ of the nuts had more than $35 \%$ of the shell surface discolored. Although most nuts with cracked hulls also had shell discoloration, the characteristics of the discoloration differed from that of early split nuts. More than $80 \%$ of the early split nuts had discoloration along the shell suture, whereas fewer than $29 \%$ of the nuts with cracked hulls had suture discoloration (Table 1). For both types of hull rupture, many of the nuts had moderate discoloration; for example, between 40 and $65 \%$ of the nuts with hull rupture had between 1 and $10 \%$ of the shell surface discolored (nuts with and without suture discoloration combined).

Among early split nuts, the type and amount of shell discoloration indicated the likelihood of kernel decay (Table 2). Little or no kernel decay occurred in early split nuts with no shell discoloration, whereas those with extensive shell discoloration (greater than $10 \%$ of the shell surface) had the highest incidence of kernel decay (Table 2). Furthermore, nuts with discoloration along the suture generally had higher incidence of fungal decay than the other nuts (Table 2). The Aspergillus spp. observed were in the sections Nigri $(97.3,88.2$, and 94.5\% of Aspergillus fungi for 1992, 1993, and 1996, respectively), Circumdati (2.7, 5.9, and 2.7\%), and Aspergillus (Eurotium spp.) $(0.0,5.9$, and $2.7 \%)$. The dematiaceous fungi with dark, multicelled conidia observed were Alternaria alternata (91.5 and $84.8 \%$ of these fungi for 1993 and 1996, respectively), Ulocladium atrum (8.5 and $12.1 \%$ ), and Dendryphiella vinosa (0.0 and $3.0 \%)$. In general, the ranking of different categories of shell discoloration according to kernel decay by Aspergillus spp. or by fungi with dark, multicelled conidia matched the ranking for incidence of kernel decay by all fungi (Table 2).

Table 2. Incidences of fungal decay and insect infestation in kernels from early split pistachio nuts (collected from commercial orchards) according to type of shell discoloration ${ }^{\mathrm{w}}$

\begin{tabular}{|c|c|c|c|c|c|c|c|c|c|c|c|}
\hline \multirow{2}{*}{\multicolumn{2}{|c|}{ Shell discoloration ${ }^{\mathrm{x}}$}} & \multicolumn{10}{|c|}{ Percentage of nuts infected or infested by the specified organisms } \\
\hline & & \multicolumn{3}{|c|}{ Aspergillus spp. } & \multicolumn{2}{|c|}{ Alternaria/Ulocladium ${ }^{\mathrm{y}}$} & \multicolumn{2}{|c|}{ All fungi combined } & \multicolumn{3}{|c|}{ Navel orangeworm } \\
\hline Suture & General & 1992 & 1993 & 1996 & 1993 & 1996 & 1993 & 1996 & 1992 & 1993 & 1996 \\
\hline No & $0 \%$ & $0.0 \mathrm{a}^{\mathrm{z}}$ & $0.0 \mathrm{a}$ & $0.0 \mathrm{a}$ & $0.0 \mathrm{a}$ & $0.5 \mathrm{a}$ & $0.0 \mathrm{a}$ & $0.5 \mathrm{a}$ & $0.0 \mathrm{a}$ & $0.0 \mathrm{a}$ & $1.0 \mathrm{a}$ \\
\hline No & 1 to $10 \%$ & $0.0 \mathrm{a}$ & $4.7 \mathrm{~b}$ & $0.0 \mathrm{a}$ & $4.7 \mathrm{ab}$ & $0.9 \mathrm{a}$ & $9.5 \mathrm{ab}$ & $3.8 \mathrm{a}$ & $4.8 \mathrm{a}$ & $4.7 \mathrm{ab}$ & $5.2 \mathrm{ab}$ \\
\hline Yes & 1 to $10 \%$ & $11.6 \mathrm{~b}$ & $6.6 \mathrm{~b}$ & $2.5 \mathrm{~b}$ & $16.9 \mathrm{ab}$ & $16.6 \mathrm{~b}$ & $23.1 \mathrm{~b}$ & $36.4 \mathrm{~b}$ & $4.6 \mathrm{a}$ & $7.3 \mathrm{bc}$ & $9.5 \mathrm{~b}$ \\
\hline Yes & $>10 \%$ & $19.9 \mathrm{c}$ & $4.9 \mathrm{~b}$ & $3.5 \mathrm{~b}$ & $37.5 \mathrm{~b}$ & $39.8 \mathrm{c}$ & $45.7 \mathrm{c}$ & $79.7 \mathrm{c}$ & $21.2 \mathrm{~b}$ & $13.6 \mathrm{c}$ & $15.7 \mathrm{c}$ \\
\hline
\end{tabular}

w Numbers of early splits examined were 524 from orchard A in 1992, 386 from orchards B and E in 1993, and 1,594 from orchard F in 1996. In 1992, Aspergillus fungi were the only fungi noted during the evaluations.

${ }^{\mathrm{x}}$ Suture discoloration means relatively large amounts of discoloration within $2 \mathrm{~mm}$ of the shell suture or split. General shell discoloration refers to the percentage of the external shell surface that was discolored regardless of location.

y Fungi with dark, multicelled conidia; predominantly Alternaria alternata and Ulocladium atrum were isolated from these colonies.

${ }^{\mathrm{z}}$ Numbers followed by the same letter are not significantly different $(P=0.05)$ by pairwise comparisons using Fisher's LSD. 
The amount of shell discoloration for early split nuts also indicated the likelihood of infestation by navel orangeworm (NOW) (Table 2). For example, nuts with no discoloration had little or no infestation, while nuts with greater than $10 \%$ of the shell surface discolored had the highest incidence of infestation (Table 2). For moderately discolored nuts (1 to $10 \%$ of surface), the incidence of infestation for nuts with discoloration along the suture was not statistically different than that for nuts without discoloration along the suture (Table 2). Only five out of 126 infested early split nuts in 1996 had NOW pupae, and the rest had NOW larvae or obvious larval damage and frass. The nuts with pupae always had more than $65 \%$ of the shell surface discolored (data not shown). In 1996, the severely discolored nuts had severe NOW damage to the kernel. The percentage of infested nuts with moderate to severe kernel damage (more than $7 \%$ of the kernel surface) was $0 \%$ (0 nuts with damage/2 infested nuts) for nuts with no discoloration, $0 \%(0 / 5)$ for nuts with no suture but moderate discoloration, $24 \%$ (10/42) for nuts with suture and moderate discoloration, and $47 \%(36 / 77)$ for nuts with extensive discoloration.

Nuts with cracked hulls sometimes had kernels decayed by fungi, although at substantially lower incidences than for the early split nuts. In 1992, only $1.7 \%$ of the nuts with cracked hulls had kernels decayed by Aspergillus fungi compared with $13.0 \%$ of the early split nuts $(P<0.001$, Fisher's exact test, data not shown). Similarly in 1996, none of the kernels within nuts with cracked hulls had decay by Aspergillus fungi, but $2.9 \%$ of kernels from early split nuts had the decay $(P<0.05$, Fisher's LSD). Also in 1996, nuts with cracked hulls had lower incidences than early split nuts for kernel decay caused by fungi with dark, multicelled conidia (1.2 versus $23.4 \%$; $P<0.05)$ and all types of fungi (6.7 versus $48.5 \%$; $P<0.01$ ). Incidence of NOW infestation in nuts with cracked hulls (7.0 and 9.6\% in 1992 and 1996, respectively) was similar to that in early split nuts $(10.3$ and $11.0 \%, P>0.30$, data not shown).

As with early split nuts, the amount of shell discoloration on nuts with cracked hulls indicated the likelihood of kernel decay. For nuts with cracked hulls from the four orchards in 1992 , only $0.1 \%$ of nuts with no discoloration of the shell surface were decayed by Aspergillus fungi compared with $14.9 \%$ of nuts with greater than $10 \%$ discoloration $(P<0.05$, Fisher's LSD, data not shown). Similarly in 1996, only $1.0 \%$ of nuts with no discoloration were decayed by fungi, whereas $25.0 \%$ of nuts with greater than $10 \%$ shell discoloration were decayed $(P<0.05$, Fisher's LSD). For moderate shell discoloration (1 to $10 \%$ of surface), 4.1 and $2.7 \%$ of nuts were decayed for 1992 and 1996, respec- tively (incidence not significantly different from that in other discoloration categories, $P>0.05)$. In addition, for nuts with cracked hulls in 1992 and 1996, nuts with no shell discoloration had less than $0.5 \%$ of nuts infested by NOW, whereas more than $7 \%$ of nuts with extensive shell discoloration (that is, greater than $10 \%$ ) were infested with NOW $(P<0.05)$.

Shell discoloration and kernel quality in nuts from processing plants. The appearance of the shell for a processed nut indicated the likelihood that the kernel was decayed by fungi and infested by NOW (Table 3). Nuts with no shell discoloration did not have kernels decayed by fungi or infested with NOW (Table 3). Nuts with some types of shell discoloration, such as extensive dark brown discoloration or with moderate dark brown discoloration along the suture, frequently had decayed and NOW-infested kernels (Table 3). However, other types of discoloration, such as yellow discoloration or moderate dark brown not along the suture, did not indicate a poor quality kernel (Table 3). The amount of yellow discoloration on the shells was frequently extensive. For example, more than $35 \%$ of the shell surface had yellow discoloration for 65 and $60 \%$ of the nuts from processors $\mathrm{A}$ and $\mathrm{B}$, respectively. Although more than $80 \%$ of the fungi causing kernel decay could not be identified because of the lack of sporulating structures, certain fungi could be identified, such as dematiaceous fungi with dark, multicelled conidia $(6.9$ and $7.1 \%$ of the decayed nuts for processors A and B (bins 1 and 2), respectively), Aspergillus section Nigri (6.9 and 3.6\%), and Penicillium spp. (1.5 and $0.7 \%)$.

For both processors, nuts with an oilyshell appearance had the highest incidences of fungal decay and NOW infestation (Table 3). Most of the fungal decay present in nuts with oily shells was in nuts infested with NOW. All of the NOW-infested nuts with oily shells had kernel decay, whereas only 21 and $42 \%$ of the noninfested nuts were decayed for processors $\mathrm{A}$ and $\mathrm{B}$, respectively (differences between infested and noninfested nuts were significant by Fisher's exact test, $P<0.001)$. NOW-infested oily-shell nuts had higher incidences of NOW pupae (69 and $86 \%$ for processors $\mathrm{A}$ and $\mathrm{B}$, respectively, data not shown) than infested nuts without oily shells (41 and $36 \%)$.

Nuts with a crinkled, distorted shell had relatively high incidences of kernel decay and NOW infestation (Table 3). Furthermore, at both processors, $92 \%$ of nuts with crinkled shells had discolored shells. In addition, 55 and $21 \%$ of nuts with crinkled shells (for processors $\mathrm{A}$ and $\mathrm{B}$, respectively) had discoloration along the suture and moderate discoloration (1 to $10 \%$ of the shell surface discolored), whereas 34 and $68 \%$ had greater than $10 \%$ discoloration.

Quantitative relationship between shell discoloration and kernel quality. In general, the pistachio nuts with more shell discoloration had poorer quality kernels than nuts with little or no shell discoloration for both early split nuts in commercial orchards and processed nuts from commercial processors (Fig. 1). The incidence of kernel decay caused by all fungi increased quadratically as the shell discoloration ratings increased for nuts from orchards $\mathrm{F}$ and $\mathrm{H}$ and processors $\mathrm{A}$ and $\mathrm{B}$ bin 3 (Fig. 1A). Moreover, incidence of kernel decay also increased quadratically as a function of shell discoloration ratings for orchard $\mathrm{G}$ in $1996\left(y=4.65+59.66 * x-9.38 * x^{2}, r^{2}=\right.$ $0.97)$ and processor B bin $1(y=1.94+$ $\left.3.66 * x+2.32 * x^{2}, r^{2}=0.96\right)$ but increased linearly for processor B bin $2(y=-4.39+$ $10.60 * x, r^{2}=0.72$ )

The incidence of kernel decay caused by Aspergillus spp. increased linearly as the shell discoloration rating increased for early split nuts in commercial orchards but not for processed nuts (Fig. 1B). For both processors, however, nuts with shell dis-

Table 3. Relationship of external shell appearance to fungal colonization and navel orangeworm (NOW) infestation in processed pistachio nuts from two processors ${ }^{\mathrm{x}}$

\begin{tabular}{|c|c|c|c|c|}
\hline \multirow[b]{2}{*}{ External appearance of shelly } & \multicolumn{2}{|c|}{ Fungal growth in kernel (\%) } & \multicolumn{2}{|c|}{ NOW infested (\%) } \\
\hline & $\mathbf{A}$ & B & $\mathbf{A}$ & B \\
\hline Oily & $71.3 \mathrm{a}^{\mathrm{z}}$ & $63.7 \mathrm{a}$ & $64.0 \mathrm{a}$ & $36.3 \mathrm{a}$ \\
\hline Crinkled & $31.2 \mathrm{~b}$ & $22.7 \mathrm{~b}$ & $8.7 \mathrm{~b}$ & $2.2 \mathrm{~b}$ \\
\hline Extensive dark brown discoloration & $16.9 \mathrm{c}$ & $26.6 \mathrm{~b}$ & $2.4 \mathrm{bc}$ & $2.2 \mathrm{~b}$ \\
\hline $\begin{array}{l}\text { Discoloration moderate, dark brown, } \\
\text { and along suture }\end{array}$ & $23.7 \mathrm{bc}$ & $18.7 \mathrm{~b}$ & $2.3 \mathrm{bc}$ & $0.7 \mathrm{bc}$ \\
\hline $\begin{array}{l}\text { Discoloration moderate, dark brown, } \\
\text { but not along suture }\end{array}$ & $0.0 \mathrm{~d}$ & $0.0 \mathrm{c}$ & $0.0 \mathrm{c}$ & $0.0 \mathrm{c}$ \\
\hline Yellow discoloration (no dark brown) & $0.6 \mathrm{~d}$ & $0.0 \mathrm{c}$ & $0.6 \mathrm{bc}$ & $0.0 \mathrm{c}$ \\
\hline Nonstained & $0.0 \mathrm{~d}$ & $0.0 \mathrm{c}$ & $0.0 \mathrm{c}$ & $0.0 \mathrm{c}$ \\
\hline
\end{tabular}

${ }^{\mathrm{x}}$ For each category of shell appearance, two and four replications of approximately 40 nuts were evaluated for processors A and B (bins 1 and 2), respectively.

${ }^{y}$ Nuts were sorted in the order given in the table. For example, all nuts with oily shells were removed first, then nuts with crinkled shells, and so on. Moderate discoloration means 1 to $10 \%$ of the external shell surface was discolored, whereas extensive means more than $10 \%$.

${ }^{\mathrm{z}}$ Statistical analysis was performed on arcsine-transformed data. Numbers followed by the same letter are not significantly different $(P=0.05)$ by pairwise comparisons using Fisher's LSD. Values presented were back-transformed from the means for the arcsine-transformed data. 
coloration occasionally had kernels decayed by Aspergillus spp., whereas no such decay was observed in processed nuts with no shell discoloration. Among the Aspergillus fungi observed, 88, 82, and $90 \%$ were in Aspergillus section Nigri for orchard $\mathrm{G}$ in 1996, orchard H in 1997, and processor B bin 3, respectively (results for the other samples were presented above). Other Aspergillus spp. isolated were A. flavus and A. melleus for orchard $\mathrm{G}$ in 1996 and A. wentii, A. ochraceus, A. melleus, A. versicolor, A. sydowii, A. carneus, and A. terreus for orchard $\mathrm{H}$ in 1997.

For decay caused by dematiaceous fungi with dark, multicelled conidia, the incidence of decay increased linearly as the shell discoloration rating increased for early split nuts from orchards F, G ( $y=$ $\left.9.64+13.09 * x, r^{2}=0.84\right)$, and $\mathrm{H}$ but quadratically for processor B (Fig. 1C). The fungi isolated were Alternaria alternata ( 95.5 and $72.2 \%$ of these fungi for orchard G in 1996 and orchard H in 1997, respectively), Ulocladium atrum (2.7 and 19.6\%), Dendryphiella vinosa (0.0 and 5.2\%), Cur- vularia spp. (1.8 and 2.1\%), and Epicoccum spp. (0.0 and $1.0 \%)$.

We also examined the processed nuts for discoloration of the kernel, because frequently the fungi appeared to be restricted to the testa without invading deeper into the kernel. Only 2.0 and $4.3 \%$ of the nuts with no shell discoloration had kernel discoloration or damage beneath the testa for processors $\mathrm{A}$ and $\mathrm{B}$, respectively; whereas the percentage of nuts with internal kernel discoloration or damage ranged from 31.9 and $16.1 \%$ to 49.0 and $27.2 \%$ as the shell discoloration rating increased from 1 to 4 for processors $\mathrm{A}$ and $\mathrm{B}$, respectively (data not shown). As the shell discoloration rating increased, the percentage of nuts with discolored or damaged kernels increased quadratically for processor A $(y=5.04+$ $\left.25.07 * x-3.66 * x^{2}, r^{2}=0.87\right)$ and linearly for processor B $\left(y=6.07+8.40^{*} x, r^{2}=\right.$ $0.88)$.

The likelihood of NOW infestation was indicated by the amount of shell discoloration. Although the regressions were not statistically significant for orchard $\mathrm{H}$ in 1997 (Fig. 1D), the incidence of NOW increased linearly as the shell discoloration rating increased for early split nuts from orchard F (Fig. 1D) and orchard G $(y=$ $\left.-0.58+2.21 * x, r^{2}=0.57\right)$ in 1996 and orchard A in $1992\left(y=0.67+6.93 * x, r^{2}=\right.$ 0.72 ). For processed nuts, the incidence of NOW increased linearly for processor A (Fig. 1D) and quadratically for processor B bin $1\left(y=0.77-2.67 * x+1.35 * x^{2}, r^{2}=\right.$ 0.78 ) as the shell discoloration rating increased. For processor B bin 3, the quadratic regression was significant, although there was not a consistent increase in incidence of NOW as the amount of shell discoloration increased (Fig. 1D). Nevertheless, in this case, all nuts with shell discoloration (rating greater than 0) had higher levels of NOW than nonstained nuts.

\section{DISCUSSION}

Nuts that rupture their hulls before harvest, such as early split nuts and those with cracked hulls, usually have discolored shells, although the amount of discoloration can vary substantially (Table 1). Early split nuts typically have more shell discol-
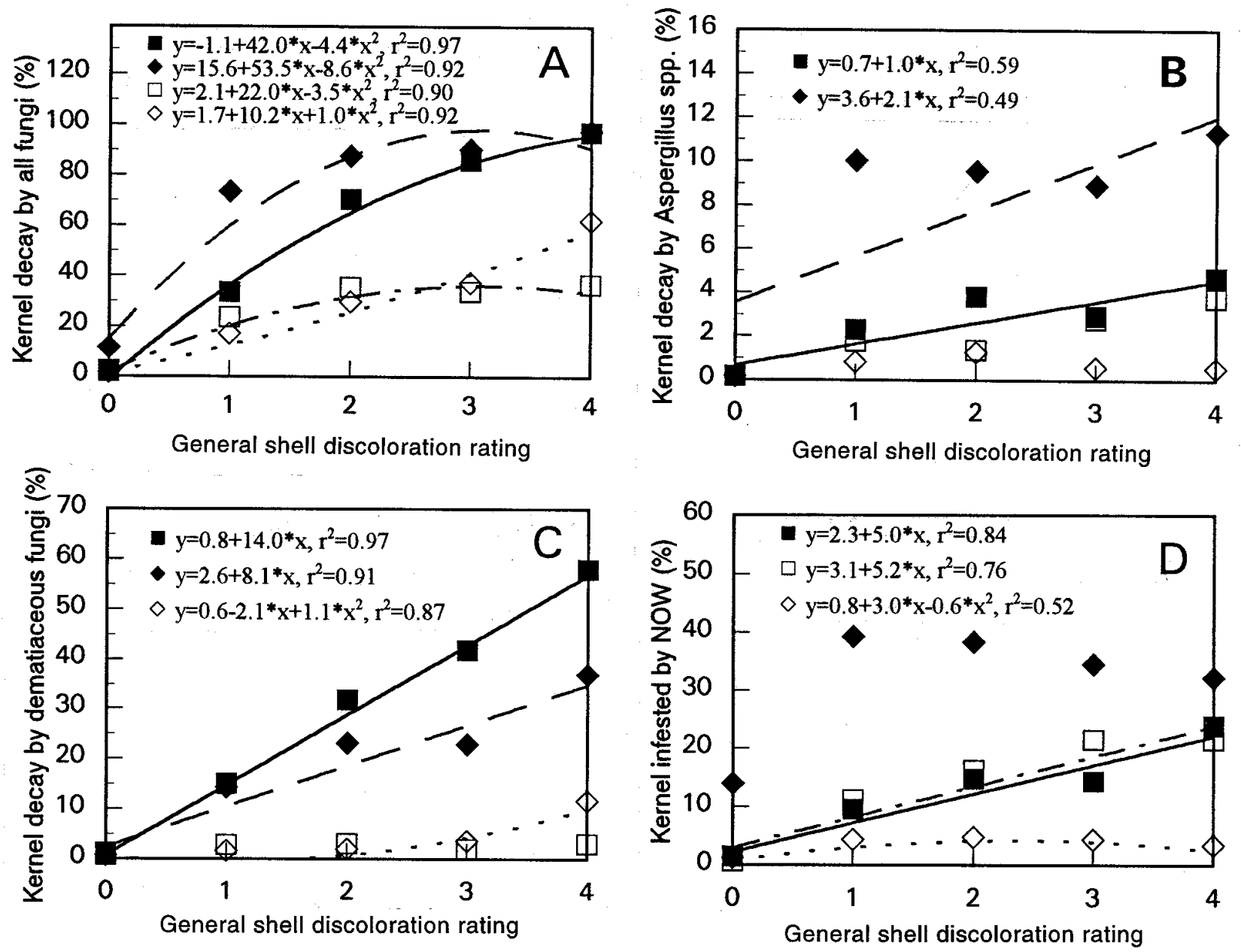

Fig. 1. Relationship between shell discoloration rating $(0=0 \%$ of external shell surface discolored, $1=1$ to $10 \%, 2=11$ to $35 \%, 3=36$ to $64 \%, 4=65$ to $100 \%)$ and kernel quality in early split nuts from two orchards ( $\boldsymbol{\square}$ orchard F, 1996; $\bullet$ orchard H, 1997) and in processed pistachio nuts from two processors ( $\square$ processor A; $\diamond$ processor B bin 3). (A) kernel decay by fungi (all species combined); (B) kernel decay by Aspergillus spp.; (C) kernel decay by dematiaceous fungi with dark, multicelled conidia (predominantly Alternaria alternata and Ulocladium atrum); (D) kernel infestation by navel orangeworm. 
oration than nuts with cracked hulls, and early split nuts are more likely to have discoloration along the shell suture than nuts with cracked hulls (Table 1). Although the cause of shell discoloration of early split nuts is unknown, wounding of hulls by insects is associated with discoloration due to peroxidase activity in the hull (1). Possibly the peroxidase activity resulting from rupturing of the hull is responsible for the shell discoloration of early split nuts. Nevertheless, some nuts have shells discolored due to causes other than hull rupture. Examples of other causes of shell discoloration are hemipteran damage (27), natural breakdown of hulls due to late harvesting $(2,7,8,19)$, colonization of hulls by fungi such as Alternaria (21), and discoloration from unknown causes such as endocarp necrosis and stylar-end lesions (27). The distinctive discoloration along the shell suture of early split nuts can be used to distinguish early split nuts from those nuts discolored by other causes.

The type of shell discoloration of early split nuts indicates the likelihood of kernel decay. Discoloration along the shell suture was previously shown to be a characteristic of early split nuts $(3,5,25)$. Even so, not all early split nuts have this distinctive discoloration along the suture (Table 1), and no relationship between kernel decay and the type of shell discoloration of early split nuts had been shown. In our study, the early split nuts with suture discoloration had more kernel decay caused by Aspergillus spp., by fungi with dark, multicelled conidia (predominantly Alternaria alternata and Ulocladium atrum), and by all types of fungi combined than did early split nuts with no suture discoloration (Table 2).

In addition to type of discoloration, amount of discoloration is an important indicator of kernel decay for early split nuts. As the amount of shell discoloration increased, so did the likelihood of kernel decay by all types of fungi combined (Fig. 1A, Table 2), Aspergillus spp. (Fig. 1B), and dematiaceous fungi with multicelled conidia (predominantly Alternaria alternata) (Fig. 1C, Table 2). In addition, the earlier in the summer that an early split nut ruptures the hull, the more extensive the shell discoloration (6). Possibly, the amount of kernel decay increases with increasing shell discoloration because the nuts with the most shell discoloration split earlier in the summer, allowing more time for colonization by fungi than in nuts with less shell discoloration.

The shell discoloration of pistachio nuts also indicates the likelihood of infestation by navel orangeworm (NOW), which is an important insect pest in pistachio nuts in California (26). As the amount of discoloration increased, so did the incidence of NOW infestation (Fig. 1D, Table 2). Besides the damage NOW larvae cause to the kernel, NOW infestation is associated with higher levels of decay by Aspergillus spp. and aflatoxin contamination $(5,28)$. Damage by NOW is especially important before harvest, because NOW usually does not survive commercial processing (13). Even though detection of NOW damage in pistachio nuts using X-ray images is being developed (14), use of shell discoloration still provides an alternative and practical method for removal of NOW-infested nuts that is easy to implement.

The appearance of the shell of commercially processed nuts (after hull removal, dehydration, and storage) indicates the quality of the kernel. Processed nuts with oily shells, crinkled shells, or shells having a dark brown discoloration along the suture had more kernel decay and NOW infestation than nuts with moderate dark brown discoloration that was not along the suture, with yellow shell discoloration, or with no shell discoloration (Table 3). The oily-appearing shells are probably due to leakage of oil from the kernel after damage, especially by NOW larvae, because pistachio kernels are high in oils, ranging from 45 to $67 \%$ of the kernel dry weight $(11,16)$. The high levels of fungal decay for these nuts with oily shells is probably due to the association of fungal decay with NOW infestation in early split pistachio nuts (5). Many of the nuts with crinkled shells, a developmental disorder also designated as "damage by other means" by processors (20), were probably early split nuts, because they had the characteristic dark brown discoloration along the suture. The high incidences of kernel decay and NOW infestation of nuts with crinkled shells is another indication that these nuts had ruptured their hulls before harvest. The color, location, and amount of the shell discoloration are also important for determining which nuts are most likely to have decayed kernels (Table 3).

Overall, the results for processed nuts in our study were consistent with the expectation that early splitting was the major source of kernel decay. Specifically, the processed nuts that have the discoloration characteristic of early split nuts, such as extensive dark brown discoloration or discoloration along the suture, also have relatively high levels of kernel decay. The yellow discoloration may have resulted from natural breakdown of the hull of lateharvested nuts and does not necessarily represent nuts with ruptured hulls. In general, nuts used in our study were not harvested late, so the normal nuts with intact hulls had little discoloration. Our results suggest that shell characteristics may be used by processors with machines (24) or hand sorters to remove decayed and infested nuts, and to improve the quality of pistachio nuts sold to consumers.

\section{ACKNOWLEDGMENTS}

We thank L. D. Boeckler and D. P. Morgan for their excellent technical assistance and the pista- chio growers and processors for their cooperation in this research.

\section{LITERATURE CITED}

1. Bostock, R. M., Thomas, C. S., Ogawa, J. M. Rice, R. E., and Uyemoto, J. K. 1987. Relationship of wound-induced peroxidase activity to epicarp lesion development in maturing pistachio fruit. Phytopathology 77:275-282.

2. Crane, J. C. 1978. Quality of pistachio nuts as affected by time of harvest. J. Am. Soc. Hortic. Sci. 103:332-333.

3. Doster, M. A., and Michailides, T. J. 1992. Characterization of pistachio nuts contaminated with aflatoxin. (Abstr.) Phytopathology 82:1146-1147.

4. Doster, M. A., and Michailides, T. J. 1993 Characteristics of pistachio nuts with Aspergillus molds. Pages 64-68 in: Calif. Pistachio Industry Annu. Rep. Crop Year 1992-1993.

5. Doster, M. A., and Michailides, T. J. 1994 Aspergillus molds and aflatoxins in pistachio nuts in California. Phytopathology 84:583590.

6. Doster, M. A., and Michailides, T. J. 1995 The relationship between date of hull splitting and decay of pistachio nuts by Aspergillus species. Plant Dis. 79:766-769.

7. Doster, M. A., and Michailides, T. J. 1997. The effect of delaying harvest on pistachio nut quality. Pages 82-84 in: Calif. Pistachio Industry Annu. Rep. Crop Year 1996-1997.

8. Doster, M. A., and Michailides, T. J. 1998. Effect of delaying harvest on pistachio nut quality. Pages 77-79 in: Calif. Pistachio Industry Annu. Rep. Crop Year 1997-1998.

9. Ellis, M. B. 1971. Dematiaceous Hyphomycetes. Commonw. Mycol. Inst., Kew, Eng.

10. Ellis, M. B. 1976. More Dematiaceous Hyphomycetes. Commonw. Mycol. Inst., Kew, Eng.

11. Garcia, J. M., Agar, I. T., and Streif, J. 1992 Fat content and fatty acid composition in individual seeds of pistachio varieties grown in Turkey. Gartenbauwissenschaft 57:130-133.

12. Heperkan, D., Aran, N., and Ayfer, M. 1994 Mycoflora and aflatoxin contamination in shelled pistachio nuts. J. Sci. Food Agric. 66:273-278.

13. Johnson, J. A., Gill, R. F., Valero, K. A., and May, S. A. 1996. Survival of navel orangeworm (Lepidoptera: Pyralidae) during pistachio processing. J. Econ. Entomol. 89:197203.

14. Keagy, P. M., Schatzki, T. F., and Parvin, B. 1996. Machine recognition of navel orange worm damage in X-ray images of pistachio nuts. Lebensm. Wiss. Technol. 29:140-145.

15. Klich, M. A., and Pitt, J. I. 1988. A Laboratory Guide to Common Aspergillus Species and Their Teleomorphs. CSIRO, Division of Food Processing, North Ryde, Australia.

16. Labavitch, J. M., Heintz, C. M., Rae, H. L., and Kader, A. A. 1982. Physiological and compositional changes associated with maturation of 'Kerman' pistachio nuts. J. Am. Soc. Hortic. Sci. 107:688-692.

17. Little, T. M. 1985. Analysis of percentage and rating scale data. HortScience 20:642-644.

18. Little, T. M., and Hills, F. J. 1978. Agricultural Experimentation. John Wiley \& Sons, New York.

19. Maranto, J., and Crane, J. C. 1982. Pistachio Production. Leaflet 2279. Division of Agricultural Sciences, University of California, Oakland.

20. Metheney, P., Baughn, L., Ferguson, L., Cruz, H., Fabbri, A., Dollo, L., Bentley, W., and Polito, V. 1995. Crop load related deformity of developing Pistacia vera cv. 'Kerman' nuts. Acta Hortic. 419:79-84.

21. Michailides, T. J., Morgan, D. P., and Doster, M. A. 1995. Diseases of pistachios in Califor- 
nia and their significance. Acta Hortic. 419:337-343.

22. Mojtahedi, H., Rabie, C. J., Lubben, A., Steyn, M., and Danesh, D. 1979. Toxic Aspergilli from pistachio nuts. Mycopathologia 67:123-127.

23. Moss, M. O. 1994. Biosynthesis of Aspergillus toxins - Non-aflatoxins. Pages 29-50 in: The Genus Aspergillus. K. A. Powell, A. Rennick, and J. F. Peberdy, eds. Plenum Press, New York.
24. Pearson, T. 1996. Machine vision system for automated detection of stained pistachio nuts. Lebensm. Wiss. Technol. 29:203-209.

25. Pearson, T. C., Slaughter, D. C., and Studer, H. E. 1994. Physical properties of pistachio nuts. Trans. ASAE 37:913-918.

26. Rice, R. E., Bentley, W. J., and Beede, R. H. 1988. Insect and Mite Pests of Pistachios in California. Publ. 21452. Division of Agriculture and Natural Resources, University of California, Oakland.
27. Rice, R. E., Uyemoto, J. K., Ogawa, J. M. and Pemberton, W. M. 1985. New findings on pistachio problems. Calif. Agric. 39(1) 15-19.

28. Sommer, N. F., Buchanan, J. R., and Fortlage, R. J. 1986. Relation of early splitting and tattering of pistachio nuts to aflatoxin in the orchard. Phytopathology 76:692-694.

29. van Egmond, H. P., and Dekker, W. H. 1995. Worldwide regulations for mycotoxins in 1994. Natural Toxins 3:332-336. 